\title{
On-site testing and case management to improve hepatitis $C$ care in drug users: a prospective, longitudinal, multicenter study in the DAA era
}

Dana Busschots ${ }^{1,2^{*}}$ (D) Rob Bielen ${ }^{1,2}$, Özgür M. Koc ${ }^{1,2,3}$, Leen Heyens ${ }^{1,2,3}$, Eefje Dercon ${ }^{4}$, Rita Verrando ${ }^{4}$, Filip Janssens ${ }^{5}$, Luc Van den Bergh ${ }^{6}$, Peter Van Lint ${ }^{7}$, Liesbeth Bruckers ${ }^{8}$, Frederik Nevens ${ }^{9}$ and Geert Robaeys ${ }^{1,2,9}$

\begin{abstract}
Background: Screening and treatment of hepatitis $\mathrm{C}$ virus (HCV) infection in people who use drugs (PWUD) remains insufficient. Reducing the burden of HCV infection in PWUD requires interventions focusing on the different steps of the HCV care cascade.

Methods: We performed a prospective, multicenter study, evaluating the impact of an HCV care model on the HCV care cascade among PWUD attending an addiction care center in Belgium between 2015 and 2018. Interventions within the care model consisted of pre-test counseling, on-site HCV screening and case management services. A multiple logistic regression model was performed to identify the independent factors influencing the outcomes.

Results: During the study period, 441 PWUD were registered at the addiction care center, 90\% (395/441) were contacted, 88\% (349/395) were screened for HCV infection. PWUD were more likely to be screened if they had ever injected drugs ( $p$ <.001; AOR 6.411 95\% Cl 3.464-11.864). In 45\% (157/349), the HCV antibody (Ab) test was positive, and in 27\% (94/349) HCV RNA was positive. Within the Belgian reimbursement criteria (fibrosis stage $\geq$ F2), 44\% (41/ 94) were treated. Specialist evaluation at the hospital was lower for PWUD receiving decentralized opioid agonist therapy ( $p=.005$; AOR $0.43095 \% \mathrm{Cl} 0.005-0.380$ ), PWUD with unstable housing in the past 6 months before inclusion ( $p=.015$; AOR $0.03595 \% \mathrm{Cl} 0.002-0.517$ ) or if they were recently incarcerated $(p=.001$; AOR $0.01095 \% \mathrm{Cl}$ 0.001-0.164).

Conclusions: This HCV care model demonstrated high screening, linkage to care, and treatment initiation among PWUD in Belgium. Using the cascade of care to guide interventions is easy and necessary to monitor results. This population needs guidance, not only for screening and treatment initiation but also for the long-term follow-up since one in six had cirrhosis and could develop hepatocellular carcinoma. Further interventions are necessary to increase linkage to care and treatment initiation. Universal access to direct-acting antiviral therapy from 2019 will contribute to achieving HCV elimination in the PWUD population.
\end{abstract}

\footnotetext{
* Correspondence: dana.busschots@uhasselt.be

'Faculty of Medicine and Life Sciences, Hasselt University, Martelarenlaan 42, 3500 Hasselt, Diepenbeek, Belgium

2Department of Gastroenterology and Hepatology, Ziekenhuis-Oost Limburg, Genk, Belgium

Full list of author information is available at the end of the article
}

(c) The Author(s). 2021 Open Access This article is licensed under a Creative Commons Attribution 4.0 International License, which permits use, sharing, adaptation, distribution and reproduction in any medium or format, as long as you give appropriate credit to the original author(s) and the source, provide a link to the Creative Commons licence, and indicate if changes were made. The images or other third party material in this article are included in the article's Creative Commons licence, unless indicated otherwise in a credit line to the material. If material is not included in the article's Creative Commons licence and your intended use is not permitted by statutory regulation or exceeds the permitted use, you will need to obtain permission directly from the copyright holder. To view a copy of this licence, visit http://creativecommons.org/licenses/by/4.0/. The Creative Commons Public Domain Dedication waiver (http://creativecommons.org/publicdomain/zero/1.0/) applies to the data made available in this article, unless otherwise stated in a credit line to the data. 
Trial registration: Clinical trial registration details: www.clinicaltrials.gov (NCT03106194).

Keywords: Hepatitis C, People who use drugs, Case management, Opioid agonist therapy, Care cascade, Highincome country

\section{Background}

Chronic infection with the hepatitis $\mathrm{C}$ virus $(\mathrm{HCV})$ remains a worldwide health problem. The World Health Organization (WHO) has set a target to reduce HCV infection incidence by $90 \%$ and liver-related mortality by $65 \%$ while increasing diagnosis and treatment by 2030 with the year 2015 as baseline [1]. With the development of direct-acting antivirals (DAA), HCV treatment has become very effective [2-4].

The seroprevalence of hepatitis $\mathrm{C}$ virus (HCV) is relatively low (1.0\%) in Belgium's general population [5]. However, the prevalence is increased in several subpopulations and these high-risk populations can continue to transmit the virus if risk behavior persists (e.g., injecting drug) $[6,7]$.

Accordingly, at-risk populations such as people who use drugs (PWUD) should also be treated as they are responsible for the virus's ongoing transmission [8].

A cascade of care is a well-known concept and pinpoints where gaps in services may exist and strategies can be developed to better support patients. However, only a few studies have evaluated the cascade of care in PWUD since the introduction of DAAs. These studies mainly focus on (active) people who inject drugs (PWID), which means that other risk subgroups such as stimulant users and former PWID are not reached [912]. A large study in British Colombia, Canada, showed that active PWID had the highest rates for HCV RNA testing, though the lowest for treatment initiation [13]. In addition, the treatment rates remained low in all studies, even in the DAA era.

Several barriers to $\mathrm{HCV}$ care may explain the lower rates of screening and treatment among drug users [14]. Studies show that both patients and caregivers lack knowledge about HCV infection, and stigmatization of $\mathrm{HCV}$ infection has a significant impact on admission for screening and treatment [15-17]. In a recent systematic review, interventions to enhance HCV screening, linkage to care, and treatment initiation were evaluated [18]. Two interventions were shown to improve HCV screening: (1) on-site testing with pre-test counseling and education, and (2) dried blood spot testing [18-20]. Furthermore, facilitated referral for HCV specialist evaluation and planning of specialist appointments improved linkage to care [21-23]. Integrating HCV care in addiction care centers by a multidisciplinary team with case management services can also improve treatment rates $[24,25]$. However, most studies were cross- sectional, performed in the interferon-era and PWID. Therefore, more longitudinal data are necessary from the DAA era to strive towards $\mathrm{HCV}$ elimination in PWUD.

Before 2015, there was no systematic approach to address HCV infection among PWUD in the Center for Alcohol and Drug abuse (CAD) Limburg in Belgium. A small randomized controlled trial (RCT) was conducted in 2014 at the addiction care center by Arain et al. to assess the influence on knowledge and willingness for $\mathrm{HCV}$ screening and treatment among PWUD. The single information session significantly improved $\mathrm{HCV}$ knowledge, though it did not result in higher rates for screening and treatment. However, the small number of subjects $(n=52)$ and the fact that the study was conducted in the interferon era should be considered when interpreting this study's results [7]. Hence, an urgent need for an easy-to-implement model was needed to offer HCV care to PWUD in an addiction care center. Therefore, we conducted this study. We offered several targeted interventions (pre-test counseling, on-site testing, facilitated referral) to positively influence the $\mathrm{HCV}$ cascade of care in PWUD in the addiction care center in Limburg, Belgium.

\section{Methods}

\section{Study settings}

PWUD are defined as people who have a history of drug use or who actively use drugs (excluding alcohol). Eligible participants were PWUD, older than 18 years, and registered at CAD Limburg between July 2015 and December 2018.

CAD Limburg is an organization providing addiction care (including opioid agonist therapy (OAT)) on several sites throughout the province of Limburg, Belgium. OAT is provided on-site (central provision) or is prescribed by the addiction care physician. The clients who only receive a prescription for OAT can receive their treatment at a local pharmacy (decentralized provision). Before 2015, there was no systematic approach to address HCV infection among PWUD at this facility for addiction care.

Between 2015 and 2017, DAA regimens were only reimbursed if fibrosis was staged $\geq$ F3 in Belgium [26]. As of January 2017, the reimbursement criteria have been adjusted to $\geq F 2$. Unlimited access has only been possible since 2019 [27, 28]. Besides, DAA treatment can 
only be prescribed and initiated by a hepatologist and is available only in a hospital pharmacy.

\section{Care model}

This is a longitudinal, multicenter study with a stepwise implementation of services to improve $\mathrm{HCV}$ care in PWUD.

An overview of the services provided and the changing treatment landscape throughout the study period is provided in (see Additional file 1). In the first phase (July 2015 to November 2016), one medical PhD student functioning as case manager offered on-site information on HCV infection and immediate screening by venipuncture to attending clients. Results of screening were explained on-site, and PWUD with positive HCV RNA were referred to one of the two hospitals prescribing DAA treatment at that time in Limburg.

In the second phase (December 2016 to December 2018), one nurse functioning as case manager provided these services. On a weekly basis the case manager was at the locations with central provision and at the centers with decentralized provision by appointment. The $\mathrm{HCV}$ case manager actively contacted clients, informed them about HCV infection and offered to test them for HCV. If a chronic $\mathrm{HCV}$ infection was diagnosed after blood sampling, a facilitated referral was suggested to guide the PWUD to the hospital. The case manager had regular contact with the clients and sent reminders when they were expected on an appointment.

From 2017 onwards, PWUD could be referred to all hospitals in Limburg. HCV finger-prick tests (OraQuick ${ }^{\circ}$ $\mathrm{HCV} \mathrm{Ab}$ ) were provided to replace screening by venipuncture in 2018, though HCV RNA was still assessed by venipuncture [29, 30]. A FibroScan ${ }^{\circ}$ was performed to assess liver damage in HCV RNA-positive patients who reached the hospital for a specialist evaluation (cutoffs for HCV/HIV: F0-F1 $=<7.2 \mathrm{kPa}$, $\mathrm{F} 2=7.2-9.5 \mathrm{kPa}, \mathrm{F} 3=9.5-11.5 \mathrm{kPa}, \mathrm{F} 4=>11.5 \mathrm{kPa})[31]$.

The study was approved by the Ethical Committees of Ziekenhuis Oost-Limburg, Genk, and Hasselt University (16/014 U). An amendment was approved to include all hospitals' study sites in 2017 and perform the services by a nurse as a case manager. The study protocol was registered at clinicaltrials.gov (NCT03106194). The study was conducted following the provisions of the Declaration of Helsinki and its amendments. Good clinical practice (GCP) guidelines were followed throughout the study [32].

\section{Data collection and outcomes}

Upon informed consent, a yearly face-to-face questionnaire was completed and subsequently stored using an online e-CRF software tool (Castor EDC). Screening for $\mathrm{HCV}$ infection was executed and analysis for $\mathrm{HCV} \mathrm{Ab}$ was performed using a third-generation ELISA assay (Abbott HCV 3.0 R, Abbott Diagnostic, Chicago, IL, USA). If $\mathrm{HCV}$ Ab positivity was confirmed, reflex $\mathrm{HCV}$ RNA testing was done using a quantitative real-time polymerase chain reaction (qRT-PCR).

There was no difference in the recruitment method between people at centralized sites compared to those at decentralized sites. An annual face-to-face questionnaire assessed continued risk behavior since the last study visit. For the analyses in this study, only the data from the questionnaire at the time of inclusion was used. In case of continued risk behavior, yearly HCV screening was offered. Risk behavior was only defined as active injection drug use since the last visit. The treating hepatologists filled out treatment characteristics and outcomes. The loss to follow-up (LTFU) was defined as loss of contact with the PWUD despite at least three attempts. All data were encoded and stored according to GCP practices.

\section{Endpoints of the study}

The primary objective of this study was to construct an $\mathrm{HCV}$ cascade of care for PWUD attending an addiction care center by implementing pre-test counseling, on-site testing and facilitated referral. By building a care cascade, the strengths and weaknesses of HCV care in Belgian PWUD can be exposed. The secondary objective of this study was to identify risk factors influencing this cascade of care.

\section{Statistical analysis}

Statistical analysis was performed using SPSS version 24. The cascade steps were determined: PWUD contacted for screening, screened, $\mathrm{HCV}$ antibody (Ab) positive, HCV RNA positive, specialist evaluation, started treatment and cured. To study baseline characteristics influencing rates of screening, diagnosis of chronic $\mathrm{HCV}$ infection, assessment and treatment initiation, univariate analyses were performed using the Chi-square test for categorical data. Continuous data were tested for normality and homogeneity of variances by Shapiro-Wilk and Levene values of $p>.050$. Since age at inclusion, age at the start of drug use, and duration of intravenous drug use were not normally distributed, the MannWhitney $U$ test was used to compare continuous variables. A multiple logistic regression model with a backward selection procedure was performed to identify the independent factors influencing the outcomes. Risk factors with $p<.150$ in the univariate analyses were included in the model for each outcome parameter. Exploratory, we assessed differences in the cascade of care between 2015 and 2016, 2017, and 2018. A Chisquared test or Fisher's exact test was used on the proportions of each step in the cascade. 
To demonstrate the efficacy of this screening method, with an $\alpha$ (significance) of 0.05 , statistical power of 0.8 , and $n=300$, we will need to improve screening from $9 \%$ (26/300 patients screened before 2015) to $16 \%$ [33-35].

This manuscript only shows the results of the analyses for uptake of screening and specialist evaluation. All other variables studied in this research can be found in (see Additional file 2) and (see Additional file 3).

\section{Results}

\section{Cascade of care for hepatitis C for PWUD}

Between 2015 and 2018, 89.6\% (395/441) of the PWUD were contacted and informed regarding HCV infection. Of those, $88.4 \%(349 / 395)$ were screened for HCV, 45.0\% (157/349) were HCV Ab positive, and 26.9\% (94/ 349) had a positive HCV RNA test. Figure 1 illustrates the outcome for linkage to care, treatment, and outcome for HCV RNA positive patients between 2015 and 2018 . Out of 21 individuals with information on continued risk behavior and HCV screening result, there was one $(4.8 \%)$ known reinfection.

A higher number of PWUD were contacted for screening in $2018(p=.039)$ compared to the other years. No significant differences were observed with the specialist evaluation $(p=.365)$ or initiation of antiviral treatment $(p=.388)$. During the study period, a significant decrease in HCV RNA positivity was observed $(59.2 \%$ in $2015-$ $2016,52.8 \%$ in 2017 , and $40.2 \%$ in $2018, p=.013$ ).

\section{Eligibility for treatment and follow-up}

FibroScan ${ }^{\circ}$ scores were available for $82.7 \%$ (67/81) PWUD who visited the hospital for specialist evaluation. METAVIR scores of F0-F1, F2, F3, and F4 were found in respectively 27 (40.3\%), 14 (20.9\%), 15 (22.4\%), and 11 (16.4\%) persons. Of those who reached the hospital for specialist evaluation, 40.3\% (27/67) were not eligible for treatment within the study period. Cirrhosis (F4) was present in $16.4 \%(11 / 67)$.

\section{Patient population}

In total, 441 PWUD were registered at CAD Limburg between 2015 and 2018. The total number of PWUD fluctuated over time: 312 PWUD were in follow-up in 2015-2016, 324 PWUD in 2017, and 346 PWUD in 2018. Baseline characteristics are provided in Table 1 and (see Additional file 3). Almost all PWUD had access to the Belgian health care system due to the mandatory healthcare insurance and thus had access to HCV care within the Belgian reimbursement criteria. In total, $78.0 \%(344 / 441)$ of the clients admitted to having injected drugs in the past, $32.8 \%(113 / 344)$ injected in the past 6 months. The majority of PWUD received OAT $(86.6 \%, 382 / 441)$. PWUD receiving decentralized OAT were less likely to have injected drugs $(73 \%$ vs.
$87 \% ; p=.001$ ), were more often employed (31\% vs. $14 \%$; $p=.005)$ and had more often stable housing $(80 \%$ vs. $64 \% ; p=.009)$ compared to individuals receiving centralized OAT.

\section{Factors influencing the cascade of care}

The adjusted odds ratio (AOR) for screening uptake in PWUD were highest among those who ever injected drugs $(p<.001$; AOR 6.411 95\% CI 3.464-11.864). PWUD receiving decentralized OAT were less likely to be screened ( $p<.001$; AOR 0.313 95\% CI 0.167-0.588). Specialist evaluation at the hospital was lower for PWUD receiving decentralized OAT $(p=.005$; AOR $0.43095 \%$ CI $0.005-0.380$ ), with unstable housing in the past 6 months before inclusion $(p=.015$; AOR 0.035 95\% CI $0.002-0.517)$ or if they were recently incarcerated $(p=.001$; AOR $0.01095 \%$ CI $0.001-0.164)$. No independent factors were associated with the diagnosis of chronic HCV infection or the start of treatment (see Additional file 4).

\section{Loss to follow-up}

In total, 83 of the 395 reached PWUD (21.0\%) got LTFU. Notably, 19 PWUD who were LTFU had a positive HCV RNA test. Of these PWUD, 13 reached the hospital once for specialist evaluation during the study period and were traceless after. Two were eligible for treatment, while the others were not. For nine of these 13 patients, the reason for LTFU was known: one patient died, two patients were long-term convicted, one was in long-term rehabilitation, two moved to another city/ country, two relapsed in active drug use without OAT, one was no longer connected to the OAT center.

\section{Discussion}

More data are needed within the DAA era to identify strategies to enhance $\mathrm{HCV}$ testing, linkage to care, and treatment to reach the WHO's goals [18]. This study presents an HCV care model, led by one case manager at an OAT center with different sites in Limburg, Belgium. The case manager contacted $90 \%$ of the PWUD attending the addiction care center and could screen 88\% for HCV infection between 2015 and 2018. Thus, we exceed the $16 \%$ target, which shows that this care model's implementation is very effective for $\mathrm{HCV}$ screening in PWUD in addiction care centers. Specific and novel to our multicenter model is that the case manager moved between the different sites to include PWUD actively and do an annual follow-up. Most importantly, due to the work of only one person, this care model has a tremendously positive and potentially enduring impact on $\mathrm{HCV}$ care among substance users across an entire province in Belgium. 


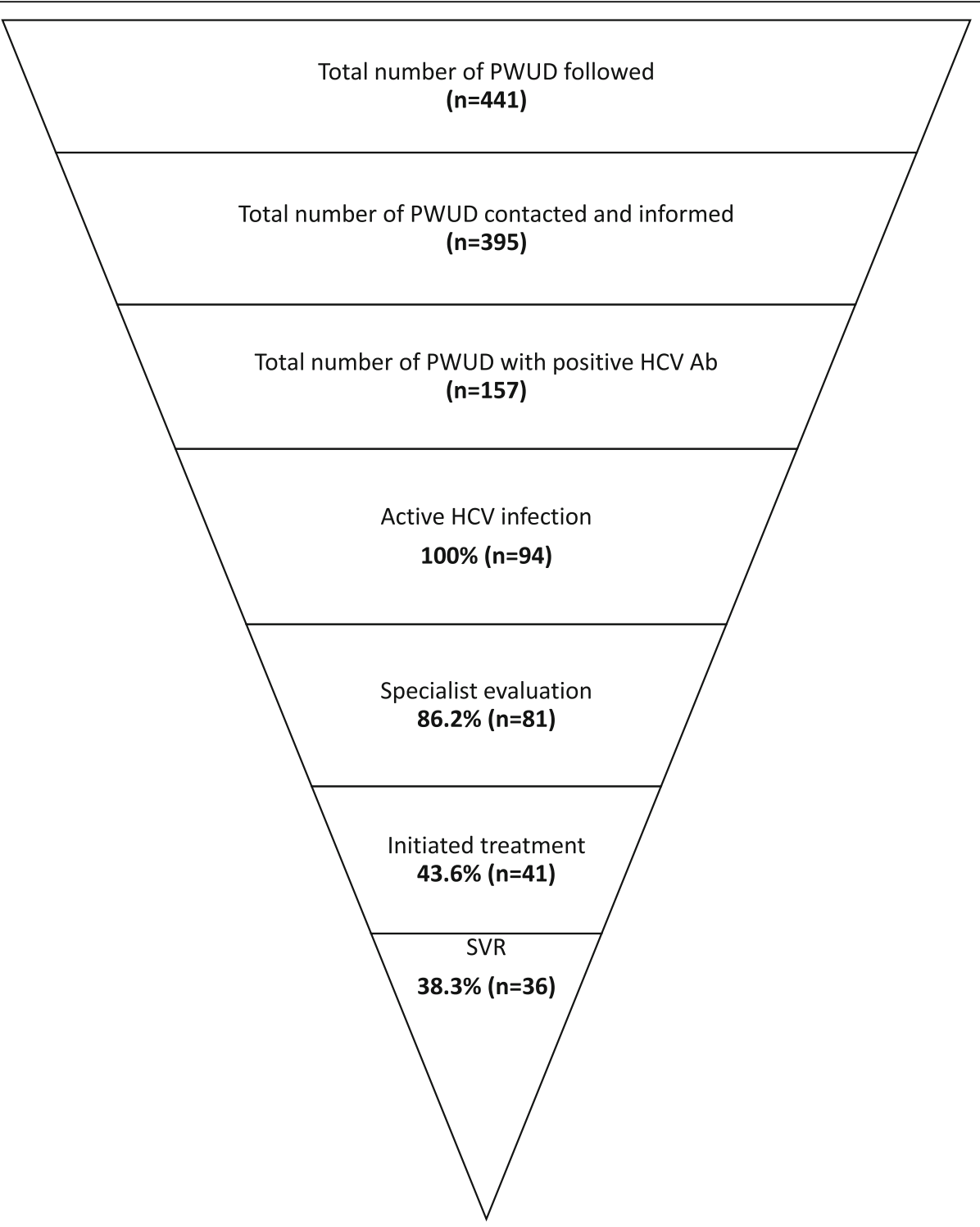

Fig. 1 The cascade of care for hepatitis C infection for people who use drugs in Limburg. Specialist evaluation of liver disease using FibroScan ${ }^{\circledR}$ was provided to 81 patients. Within the Belgian reimbursement criteria (fibrosis stage $\geq$ F2), 41 patients were treated during the study period. Abbreviations: HCV hepatitis C virus; $A b=$ antibodies; PWUD = people who use drugs; SVR = sustained virologic response

Services such as information and education on $\mathrm{HCV}$ infection were integrated at the OAT center. Targeted on-site HCV screening was carried out at all the different locations of the OAT center. Previous studies to enhance uptake for screening by on-site testing with pretest counseling varied widely, with testing rates from 18 to $86 \%$ in the interferon era $[18,36]$. Nevertheless, we reported results in the DAA era, and our yearly screening rates varied from 76 to $86 \%$, with a combined screening uptake of $89 \%$ over the 3 years. Moreover, as we compare our new results with the few data we have from before implementing this care model, the uptake of screening has increased enormously (from 9.5 to $89 \%$ ). Our results point to a large, positive impact and the need to continue this care model.

In Belgium, DAA treatment can only be prescribed by a hepatologist. Therefore, specialist evaluation needed to be performed in the hospital. To enhance linkage to care, case management services were provided to facilitate referral and appointments, and PWUD were also accompanied to the hospital if requested. Internationally, studies showed increased linkage to care ranging from 51 to $82 \%$ in studies with on-site screening, education, and/or case management services [22, 23, 25, 36]. In our setting, 
Table 1 Baseline characteristics and univariate analyses for screening of people who use drugs at the Center for Alcohol and Drug abuse in Limburg

\begin{tabular}{|c|c|c|c|}
\hline \multirow{3}{*}{ Characteristic $(n=441)$} & \multirow[b]{3}{*}{ N (\%) } & \multicolumn{2}{|l|}{ Univariate analyses } \\
\hline & & \multicolumn{2}{|l|}{ Screened for HCV $n=349$} \\
\hline & & n (n/N\%) & $p$-value \\
\hline Age $($ mean $\pm S D)$ & $42 \pm 9(19-62)$ & $43 \pm 9$ & .377 \\
\hline Gender & & & .089 \\
\hline Male & $356(80.7)$ & $276(77.5)$ & \\
\hline Female & $85(19.3)$ & $73(85.9)$ & \\
\hline Source of income & & & .008 \\
\hline Employment & $89(20.2)$ & $60(67.4)$ & \\
\hline Welfare check & $312(70.7)$ & 259(83.0) & \\
\hline Pension & $1(0.2)$ & $1(100)$ & \\
\hline None & $30(6.8)$ & $21(70.0)$ & \\
\hline Missing & $9(2.0)$ & & \\
\hline Housing last 6 months & & & 0.859 \\
\hline At home (owned/rented) & $311(70.5)$ & $243(78.1)$ & \\
\hline At the house of family/friends & 79 (17.9) & $65(82.3)$ & \\
\hline Prison & $9(2.0)$ & $8(88.9)$ & \\
\hline Mental health/drug abuse institution & $17(3.9)$ & $13(76.5)$ & \\
\hline Streets/squatted building & $17(3.9)$ & $13(76.5)$ & \\
\hline Missing & $8(1.8)$ & & \\
\hline Contact location for recruitment & & & $<.001$ \\
\hline Centralized OAT (CAD Limburg) & $211(47.8)$ & $187(88.6)$ & \\
\hline Decentralized OAT (pharmacy) & 187(42.4) & $121(64.7)$ & \\
\hline NSP & $16(3.6)$ & $15(93.8)$ & \\
\hline Former PWUD & $16(3.6)$ & $15(93.8)$ & \\
\hline Active user, no therapy & $11(2.5)$ & $11(100)$ & \\
\hline Ever been incarcerated & & & 0.018 \\
\hline Yes & $234(53.1)$ & $198(84.6)$ & \\
\hline No & $147(33.3)$ & $110(74.8)$ & \\
\hline Missing & $60(13.6)$ & & \\
\hline Incarcerated last 6 months & & & 0.828 \\
\hline Yes & $22(9.4)$ & $19(86.4)$ & \\
\hline No & $208(90.6)$ & $176(84.6)$ & \\
\hline Missing & $4(1.7)$ & & \\
\hline Alcohol abuse & & & 0.019 \\
\hline Active & $144(32.7)$ & $124(86.1)$ & \\
\hline Former & $25(5.7)$ & $23(92.0)$ & \\
\hline No & $153(34.7)$ & $146(95.4)$ & \\
\hline Missing & $119(27.0)$ & & \\
\hline Ever IDU & & & $<.001$ \\
\hline Yes & $344(78.0)$ & $302(87.7)$ & \\
\hline No & $75(17.0)$ & $40(53.3)$ & \\
\hline Missing & $22(5.0)$ & & \\
\hline
\end{tabular}


Table 1 Baseline characteristics and univariate analyses for screening of people who use drugs at the Center for Alcohol and Drug abuse in Limburg (Continued)

\begin{tabular}{|c|c|c|c|}
\hline \multirow{3}{*}{ Characteristic $(n=441)$} & \multirow[b]{3}{*}{$\mathrm{N}(\%)$} & \multicolumn{2}{|l|}{ Univariate analyses } \\
\hline & & \multicolumn{2}{|l|}{ Screened for HCV $n=349$} \\
\hline & & n (n/N\%) & $p$-value \\
\hline IDU during the last 6 months & & & $<.001$ \\
\hline Yes & $113(32.8)$ & $105(92.9)$ & \\
\hline No & $328(67.2)$ & $244(74.4)$ & \\
\hline Connected to NSP & & & .007 \\
\hline Yes & $62(15.1)$ & $59(95.2)$ & \\
\hline No & $317(77.1)$ & $258(81.4)$ & \\
\hline Missing & $32(7.8)$ & & \\
\hline
\end{tabular}

Abbreviations: SD standard deviation, OAT opioid agonist therapy, CAD center for alcohol and drug abuse, NSP needle syringe program, IDU intravenous drug use, NSP needle syringe program

specialist evaluation ranged from 69 to $77 \%$ yearly, with a combined linkage to care of $86 \%$ over 3 years.

Treatment initiation is the most difficult to compare with international findings. This differs the most due to novel, effective and safe treatments compared to the interferon era. Furthermore, the presence of (changing) reimbursement criteria makes a comparison between countries difficult $[37,38]$. Previous studies in the interferon era demonstrated the effectiveness of interventions such as nurse-facilitated referral to the hospital and integrating $\mathrm{HCV}$ care on-site with non-invasive liver disease assessment and motivational education. Treatment rates ranged from 7 to $38 \%$ in these studies [21, 24, 39]. Nevertheless, we report results in the DAA era, and yearly treatment initiation ranged from 16 to $33 \%$, with a combined treatment rate of $44 \%$. The most important reason for refusal of therapy was located at the level of the health care system. First, 14\% of all HCV RNA positives did not reach the hospital for specialist evaluation (no linkage to care). Additionally, $40 \%$ of those who reached the hospital for specialist evaluation did not reach the reimbursement criteria of a fibrosis stage $\geq$ F3 (2015) or $\geq$ F2 (2017). Of those eligible for treatment, five PWUD were refused therapy due to non-adherence. The decision to refuse therapy was always made with a multidisciplinary team (hepatologist, case manager and CAD staff). Three PWUD were incarcerated before therapy could be initiated. In Belgium, the Department of Justice regulates the prison system and not the Department of Health. Therefore, we could not initiate treatment for these patients under the supervision of the case manager. Currently, DAA treatment can only be prescribed and initiated by a hepatologist and is available only in a hospital pharmacy. If in the future, DAA therapy could be prescribed by other healthcare professionals and be available in local pharmacies, treatment access would improve, and patients would be able to receive their medication more conveniently.
PWUD on centralized OAT provision were more likely to be screened and linked to care than PWUD receiving decentralized OAT. Our intervention was implemented at the OAT center, so patients who visited often would more easily benefit from the case manager's support. Also, PWUD receiving decentralized OAT were less likely to have injected drugs, were more often employed, and had more often stable housing. Housing instability is associated with high-risk injection behavior and impacts social networks $[17,40,41]$. Outreach will be implemented during the next years to improve screening and linkage to care for PWUD in decentralized OAT.

There were limitations to this study. Our study population consisted of PWUD, who were in contact with the OAT center. Therefore, they could already be more engaged in care and might not represent the whole PWUD population. Furthermore, our study was not an RCT due to the goal of providing $\mathrm{HCV}$ care to the whole population. Except for the small historical group studied by Arain et al. in 2014, there was no comparison possible, and the impact of the various steps of our care model could not be assessed well. As there was little to no data available from the period before our study intervention, a long-term comparison was difficult. Finally, we did not collect data on coinfections, which could potentially influence screening and treatment initiation.

\section{Conclusions}

Using the cascade of care to guide interventions is easy and necessary to monitor results. Since 2019, this project has been recognized and financially supported by the Flemish government. This population needs guidance, not only for screening and treatment but also for the longterm follow-up since one in six had cirrhosis and could develop HCC. Further interventions are necessary to increase linkage to care and treatment initiation. Universal access to DAA therapy from 2019 onwards will contribute significantly to reaching HCV elimination in our cohort. 


\section{Abbreviations}

HCV: Hepatitis C virus; WHO: World Health Organization; DAA: Direct-acting antivirals; PWUD: People who use drugs; PWID: People who inject drugs; CAD: Center for Alcohol and Drug abuse; RCT: Randomized controlled trial; OAT: Opioid agonist therapy; GCP: Good clinical practice; LTFU: Loss to follow-up; Ab: Antibody; AOR: Adjusted odds ratio

\section{Supplementary Information}

The online version contains supplementary material available at https://doi. org/10.1186/s12889-021-11608-9.

Additional file 1. Changing the landscape of hepatitis $C$ virus infection treatment and services provided to people who use drugs.

Additional file 2. Univariate analysis by $\mathrm{Chi}^{2}$ test or Mann-Whitney $U$ test for characteristics of screened, RNA positive, specialist evaluation and treated people who use drugs.

Additional file 3. A multivariate regression model with backward conditional removal of variables.

Additional file 4. Baseline characteristics of people who use drugs at the Centre for Alcohol and Drug abuse in Limburg.

\section{Acknowledgments}

We thank all the clients of CAD who have generously participated in this research. We would like to thank Lou Vinken and Marcel Follon for their support in educating the hepatitis $C$ nurse on the specifics of working in an addiction setting. Furthermore, special thanks to Dr. Filip Janssens, Dr. Luc Van den Bergh, and Dr. Annelies Posen to treat patients from this study for $\mathrm{HCV}$ infection under their supervision and provide feedback on the outcome. The PhD authors are part of the Limburg Clinical Research Center (LCRC), supported by the foundation Limburg Sterk Merk, province of Limburg, Flemish government, Hasselt University, Ziekenhuis Oost-Limburg, and Jessa Hospital. D.B., F.N., and G.R. are part of the project G0B2317N funded by the Fund of Scientific Research - Flanders (FWO).

\section{Authors' contributions}

R.B. and G.R., conception and design of the study and data collection. R.B and L.B. analysis of data. R.B. and D.B. drafting of the article and finalizing the article. All co-authors: critical revision of draft and approval of the final version of the article and author list.

\section{Funding}

This project has been made possible thanks to an unrestricted grant by Gilead Sciences (2015) and a pharmaceutical grant by Merck, Sharp \& Dohme (2016-2019), registered R-7430 at Hasselt University. No direct benefits were granted to the pharmaceutical industry.

\section{Availability of data and materials}

All data generated or analyzed during this study are included in this published article and its additional files.

\section{Declarations}

\section{Ethics approval and consent to participate}

The study was first approved by the Ethical Committees of Ziekenhuis OostLimburg, Genk, and Hasselt University (16/014 U). An amendment was approved to include the study sites of all hospitals in 2017 and perform the services by an HCV case manager. The study protocol was registered at clinicaltrials.gov (NCT03106194). The study was conducted following the provisions of the Declaration of Helsinki and its amendments. Good clinical practice guidelines were followed throughout the study, and all participants provided written informed consent.

\section{Consent for publication}

Not applicable.

\section{Competing interests}

D.B. has received travel grants from AbbVie and Gilead Sciences and a research grant from Gilead. R.B. has received travel grants from AbbVie,
Gilead Sciences and MSD and research grants from Gilead and MSD. Ö.K. has received a travel grant and research grants from Gilead. F.N. has received research grants, consultancy agreements and travel grants from UCB, Ipsen, Roche, Astellas, Ferring, Novartis, Janssen-Cilag, Abbvie, Gilead, CAF, Intercept, Gore, BMS, MSD, Promethera Biosciences, Ono Pharma, Durect. G.R. has received research grants from AbbVie, Janssen Pharmaceuticals, MSD, and has acted as a consultant/advisor for AbbVie, BMS, Gilead Sciences and MSD. The other co-authors report no conflict of interest.

\section{Author details}

${ }^{1}$ Faculty of Medicine and Life Sciences, Hasselt University, Martelarenlaan 42, 3500 Hasselt, Diepenbeek, Belgium. ${ }^{2}$ Department of Gastroenterology and Hepatology, Ziekenhuis-Oost Limburg, Genk, Belgium. ${ }^{3}$ Medical Microbiology, School of NUTRIM, Maastricht University Medical Center, Maastricht, The Netherlands. ${ }^{4}$ zorGGroep Zin Limburg, Hasselt, Belgium. ${ }^{5}$ Department of Gastroenterology, Jessa Hospital, Hasselt, Belgium. ${ }^{6}$ Department of Gastroenterology, Sint-Trudo Hospital, Sint-Truiden, Belgium. ${ }^{7}$ Department of Gastroenterology, AZ Vesalius, Tongeren, Belgium. ${ }^{8}$ Faculty of Science, Center for statistics, Interuniversity Institute for Biostatistics and statistical Bioinformatics, Hasselt University, Diepenbeek, Belgium. 'Department of Gastroenterology and Hepatology, University Hospitals KU Leuven, Leuven, Belgium.

Received: 2 December 2020 Accepted: 8 August 2021

Published online: 20 August 2021

References

1. WHO. Guidelines for the screening, care and treatment of persons with chronic hepatitis C infection. Geneva: World Health Organization; 2016. p. 138.

2. Lawitz E, Sulkowski MS, Ghalib R, Rodriguez-Torres M, Younossi ZM, Corregidor A, et al. Simeprevir plus sofosbuvir, with or without ribavirin, to treat chronic infection with hepatitis $C$ virus genotype 1 in non-responders to pegylated interferon and ribavirin and treatment-naive patients: the COSMOS randomised study. Lancet. 2014;384(9956):1756-65. https://doi. org/10.1016/S0140-6736(14)61036-9.

3. Falade-Nwulia O, Suarez-Cuervo C, Nelson DR, Fried MW, Segal JB, Sulkowski MS. Oral direct-acting agent therapy for hepatitis $C$ virus infection: a systematic review. Ann Intern Med. 2017;166(9):637-48. https://doi.org/10. 7326/M16-2575.

4. Elsherif O, Bannan C, Keating S, McKiernan S, Bergin C, Norris S. Outcomes from a large 10 year hepatitis $C$ treatment programme in people who inject drugs: no effect of recent or former injecting drug use on treatment adherence or therapeutic response. PLoS One. 2017;12(6);e0178398. https:// doi.org/10.1371/journal.pone.0178398.

5. Muyldermans G, Bielen R, Botterman R, Bourgeois S, Colle I, Deressa B, et al. Hepatitis $C$ virus ( $\mathrm{HCV}$ ) prevalence estimation in the adult general population in Belgium : a meta-analysis. Acta Gastroenterol Belg. 2019;82(4):479-85.

6. Busschots D, Toghanian S, Bielen R, Salomonsson S, Koc OM, Hendrickx G, et al. Eliminating viral hepatitis $C$ in Belgium: the micro-elimination approach. BMC Infect Dis. 2020;20(1):181. https://doi.org/10.1186/s12879-020-4898-y.

7. Arain A, De Sousa J, Corten K, Verrando R, Thijs H, Mathei C, et al. Pilot study: combining formal and peer education with FibroScan to increase HCV screening and treatment in persons who use drugs. J Subst Abus Treat. 2016;67:44-9. https://doi.org/10.1016/j.jsat.2016.04.001.

8. ECDC. European Centre for Disease Prevention and Control. Annual Epidemiological Report 2016 - Hepatitis C. Stockholm: ECDC; 2016. [cited 2016 July 27]

9. Iversen J, Grebely J, Catlett B, Cunningham P, Dore GJ, Maher L. Estimating the cascade of hepatitis $C$ testing, care and treatment among people who inject drugs in Australia. Int J Drug Policy. 2017;47:77-85. https://doi.org/1 0.1016/j.drugpo.2017.05.022.

10. Butler K, Day C, Sutherland R, van Buskirk J, Breen C, Burns L, et al. Hepatitis $C$ testing in general practice settings: a cross-sectional study of people who inject drugs in Australia. Int J Drug Policy. 2017;47:102-6. https://doi.org/1 0.1016/j.drugpo.2017.07.008.

11. Stephens DB, Young AM, Havens JR. Healthcare contact and treatment uptake following hepatitis C virus screening and counseling among rural Appalachian people who use drugs. Int J Drug Policy. 2017;47:86-94. https://doi.org/10.1016/j.drugpo.2017.05.045.

12. van Santen DK, van der Helm JJ, Lindenburg K, Schim Van Der Loeff M, Prins M. HIV and hepatitis C treatment uptake among people who use 
drugs participating in the Amsterdam cohort studies, 1985-2015. Int J Drug Policy. 2017;47:95-101. https://doi.org/10.1016/j.drugpo.2017.05.026.

13. Bartlett SR, Yu A, Chapinal N, Rossi C, Butt Z, Wong S, et al. The population level care cascade for hepatitis C in British Columbia, Canada as of 2018: impact of direct acting antivirals. Liver Int. 2019;39(12):2261-72. https://doi. org/10.1111/liv.14227.

14. Arain $\mathrm{A}$, Robaeys $\mathrm{G}$. Eligibility of persons who inject drugs for treatment of hepatitis C virus infection. World J Gastroenterol. 2014;20(36):12722-33. https://doi.org/10.3748/wjg.v20.136.12722.

15. Grebely J, Tyndall MW. Management of HCV and HIV infections among people who inject drugs. Curr Opin HIV AIDS. 2011;6(6):501-7. https://doi. org $/ 10.1097 / \mathrm{COH} .0 \mathrm{~b} 013 \mathrm{e} 32834 \mathrm{bcb} 36$.

16. Miller ER, McNally S, Wallace J, Schlichthorst $M$. The ongoing impacts of hepatitis C--a systematic narrative review of the literature. BMC Public Health. 2012;12(1):672. https://doi.org/10.1186/1471-2458-12-672.

17. Dowsett LE, Coward S, Lorenzetti DL, MacKean G, Clement F. Living with hepatitis C virus: a systematic review and narrative synthesis of qualitative literature. Can J Gastroenterol Hepatol. 2017;2017:3268650.

18. Bajis S, Dore GJ, Hajarizadeh B, Cunningham EB, Maher L, Grebely J. Interventions to enhance testing, linkage to care and treatment uptake for hepatitis $C$ virus infection among people who inject drugs: a systematic review. Int J Drug Policy. 2017;47:34-46. https://doi.org/10.1016/j.drugpo.2017.07.002.

19. Hickman M, McDonald T, Judd A, Nichols T, Hope V, Skidmore S, et al. Increasing the uptake of hepatitis $\mathrm{C}$ virus testing among injecting drug users in specialist drug treatment and prison settings by using dried blood spots for diagnostic testing: a cluster randomized controlled trial. J Viral Hepat. 2008;15(4):250-4. https://doi.org/10.1111/j.1365-2893.2007.00937.x.

20. Radley A, Melville K, Tait J, Stephens B, Evans JMM, Dillon JF. A quasiexperimental evaluation of dried blood spot testing through community pharmacies in the Tayside region of Scotland. Frontline Gastroenterol. 2017; 8(3):221-8. https://doi.org/10.1136/flgastro-2016-100776.

21. Cullen W, Stanley J, Langton D, Kelly Y, Staines A, Bury G. Hepatitis C infection among injecting drug users in general practice: a cluster randomised controlled trial of clinical guidelines' implementation. Br J Gen Pract. 2006;56(532):848-56.

22. Masson CL, Delucchi KL, McKnight C, Hettema J, Khalili M, Min A, et al. A randomized trial of a hepatitis care coordination model in methadone maintenance treatment. Am J Public Health. 2013;103(10):e81-8. https://doi. org/10.2105/AJPH.2013.301458.

23. Tait JM, Mclntyre PG, McLeod S, Nathwani D, Dillon JF. The impact of a managed care network on attendance, follow-up and treatment at a hepatitis C specialist centre. J Viral Hepat. 2010;17(10):698-704. https://doi. org/10.1111/j.1365-2893.2009.01227.x.

24. Ho SB, Brau N, Cheung R, Liu L, Sanchez C, Sklar M, et al. Integrated care increases treatment and improves outcomes of patients with chronic hepatitis C virus infection and psychiatric illness or substance abuse. Clin Gastroenterol Hepatol. 2015:13(11):2005-14 e2001-2003.

25. Harney BL, Whitton B, Lim C, Paige E, McDonald B, Nolan S, et al. Quantitative evaluation of an integrated nurse model of care providing hepatitis $C$ treatment to people attending homeless services in Melbourne, Australia. Int J Drug Policy. 2019;72:195-8. https://doi.org/10.1016/j.drugpo.2 019.02.012.

26. BCFI. Recente informatie januari 2015: tapentadol, alemtuzumab, simeprevir en sofosbuvir, levothyroxine (L-thyroxine ${ }^{\oplus}$ ). [http://www.bcfi.be/nl/articles/22 71?folia=2270]. Accessed 6 Oct 2020.

27. RIZIV. Antivirale geneesmiddelen tegen hepatitis $\mathrm{C}$ : vergoedingsvoorwaarden vanaf 1 januari 2019. [https://www.riziv.fgov.be/nl/ themas/kost-terugbetaling/door-ziekenfonds/ geneesmiddelgezondheidsproduct/terugbetalen/specialiteiten/wijzigingen/ Paginas/antivirale-hepatitisc-terugbetalingsvoorwaarden_20190101.aspx]. Accessed 6 Oct 2020.

28. RIZIV. Antivirale geneesmiddelen tegen hepatitis $\mathrm{C}$ :

vergoedingsvoorwaarden vanaf 1 januari 2017. [https://www.inami.fgov.be/ nl/themas/kost-terugbetaling/door-ziekenfonds/ geneesmiddelgezondheidsproduct/terugbetalen/specialiteiten/wijzigingen/ Paginas/antiretrovirale_hepatitisc_terugbetalingsvoorwaarden_20170101.a spx]. Accessed 6 Oct 2020.

29. Chevaliez S, Poiteau L, Rosa I, Soulier A, Roudot-Thoraval F, Laperche S, et al. Prospective assessment of rapid diagnostic tests for the detection of antibodies to hepatitis $C$ virus, a tool for improving access to care. Clin Microbiol Infect. 2016;22(5):459 e451-6.
30. Tang W, Chen W, Amini A, Boeras D, Falconer J, Kelly H, et al. Diagnostic accuracy of tests to detect hepatitis $C$ antibody: a meta-analysis and review of the literature. BMC Infect Dis. 2017;17(Suppl 1):695. https://doi.org/10.11 86/s12879-017-2773-2.

31. Echosens. Quantifying fibrosis with FibroScan. [https://www.echosens.com/en/ myfibroscan-smart-app-to-manage-chronic-liverdiseases]. Accessed 7 Oct 2020.

32. International Conference of Harmonization (ICH). ICH Tripartite Guideline for Good Clinical Practices E6 (R1), June 10, 1996. [http://www.ich.org/filea dmin/Public_Web_Site/ICH_Products/Guidelines/Efficacy/E6/E6_R1_ Guideline.pdf]. Accessed 15 Oct 2020.

33. Aspinall EJ, Doyle JS, Corson S, Hellard ME, Hunt D, Goldberg D, et al. Targeted hepatitis $C$ antibody testing interventions: a systematic review and meta-analysis. Eur J Epidemiol. 2015;30(2):115-29. https://doi.org/10.1007/s1 0654-014-9958-4.

34. Cullen BL, Hutchinson SJ, Cameron SO, Anderson E, Ahmed S, Spence E, et al. Identifying former injecting drug users infected with hepatitis $C$ : an evaluation of a general practice-based case-finding intervention. J Public Health (Oxf). 2012;34(1):14-23. https://doi.org/10.1093/pubmed/fdr097.

35. Sahajian F, Bailly F, Vanhems P, Fantino B, Vannier-Nitenberg C, Fabry J, et al. A randomized trial of viral hepatitis prevention among underprivileged people in the Lyon area of France. J Public Health (Oxf). 2011;33(2):182-92. https://doi.org/10.1093/pubmed/fdq071.

36. Rosenberg SD, Goldberg RW, Dixon LB, Wolford GL, Slade EP, Himelhoch S, et al. Assessing the STIRR model of best practices for blood-borne infections of clients with severe mental illness. Psychiatr Serv. 2010;61(9):885-91. https://doi.org/10.1176/ps.2010.61.9.885.

37. Marshall AD, Pawlotsky JM, Lazarus JV, Aghemo A, Dore GJ, Grebely J. The removal of DAA restrictions in Europe - one step closer to eliminating HCV as a major public health threat. J Hepatol. 2018;69(5):1188-96. https://doi. org/10.1016/j.jhep.2018.06.016.

38. Marshall AD, Cunningham EB, Nielsen $S$, Aghemo A, Alho H, Backmund M, et al. Restrictions for reimbursement of interferon-free direct-acting antiviral drugs for HCV infection in Europe. Lancet Gastroenterol Hepatol. 2018;3(2): 125-33. https://doi.org/10.1016/S2468-1253(17)30284-4.

39. Moussalli J, Delaquaize H, Boubilley D, Lhomme JP, Merleau Ponty J, Sabot $D$, et al. Factors to improve the management of hepatitis $C$ in drug users: an observational study in an addiction centre. Gastroenterol Res Pract. 2010; 2010:1-4. https://doi.org/10.1155/2010/261472.

40. Johnson G, Chamberlain C. Homelessness and substance abuse: which comes first? Aust Soc Work. 2008;61(4):342-56. https://doi.org/10.1080/ 03124070802428191.

41. Topp L, Iversen J, Baldry E, Maher L, Collaboration of Australian N. Housing instability among people who inject drugs: results from the Australian needle and syringe program survey. J Urban Health. 2013;90(4):699-716. https://doi.org/10.1007/s11524-012-9730-6.

\section{Publisher's Note}

Springer Nature remains neutral with regard to jurisdictional claims in published maps and institutional affiliations.

Ready to submit your research? Choose BMC and benefit from:

- fast, convenient online submission

- thorough peer review by experienced researchers in your field

- rapid publication on acceptance

- support for research data, including large and complex data types

- gold Open Access which fosters wider collaboration and increased citations

- maximum visibility for your research: over $100 \mathrm{M}$ website views per year

At $\mathrm{BMC}$, research is always in progress.

Learn more biomedcentral.com/submission 